\title{
Anti-muscarinic drugs increase rectal compliance and exacerbate constipation in chronic spinal cord injury
}

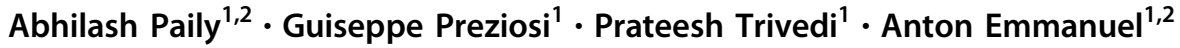

Received: 26 July 2018 / Revised: 12 February 2019 / Accepted: 13 February 2019 / Published online: 25 February 2019

(c) International Spinal Cord Society 2019

\begin{abstract}
Study design Prospective cohort study

Objectives We hypothesized that anti-muscarinic agents alter rectal compliance in SCI patients and that altered rectal compliance relates to bowel symptomatology. Our primary aim was to compare rectal compliance before and after the institution of anti-muscarinics (solifenacin and tolterodine) and an adrenoceptor agonist (mirabegron) in these patients. Additionally, we wanted to evaluate if anorectal manometry differed before and after use of anti-muscarinic agents.

Setting Tertiary neurogastroenterology clinic, London

Methods Thirty-five patients with supraconal spinal cord injury (SCI) underwent anal manometry, assessment of rectoanal inhibitory reflex (RAIR) and rectal compliance before and after anti-muscarinic treatment (for overactive bladder) was started (mean follow-up 12 weeks). Patients were assessed identically, pre-and post-treatment (solifenacin $n=17$, tolterodine $n=10$, mirabegron $n=8$ ). Doses used were as for non-SCI patients.

Results Resting, squeeze and cough pressures were unchanged after anti-muscarinic treatment. Rectal compliance was significantly raised after anti-muscarinic treatment $(p=0.001)$. The percent amplitude of maximal sphincter relaxation of the RAIR was decreased $(p<0.001)$ and excitation latency was increased $(p=0.006)$. There was no significant change in the duration of recovery of the RAIR. There was a significant increase of the Wexner Constipation Score $(p=0.001)$ but no change in the Wexner Incontinence Score. There was a significant correlation between change in rectal compliance and change in Wexner Constipation Score $(p=0.001)$. Thus, increasing compliance of the rectum is associated with worsening of constipation after anti-muscarinic therapy. However, there were no changes in anorectal manometry or rectal compliance in those who received mirabegron.
\end{abstract}

Conclusion Anti-muscarinic therapy for overactive bladder increases compliance of the neurogenic rectum and alters anorectal reflex activity, with worsening of constipation.

\section{Introduction}

Patients with spinal cord injury (SCI) experience the debilitating effects of bowel dysfunction, which is the result of the disturbance in the co-ordination of the spinal

Abhilash Paily

ajpaily@hotmail.com

1 Department of GI Physiology, University College London Hospital, 235 Euston Road, London NW1 2BU, UK

2 Department of Gastroenterology, Spinal Injuries Unit, Royal National Orthopaedic Hospital, Brockley Hill, Stanmore, Middlesex HA7 4LP, UK autonomic nervous system, voluntary cortical control and the intrinsic (enteric) nervous system. Bowel dysfunction affects approximately $80 \%$ of patients with spinal cord injury [1] and has a significant adverse effect on quality of life [1-3]. Although a wide spectrum of symptom patterns exist, constipation is the most common bowel complaint [4-7]. The aetiology of constipation in such patients is multi-factorial, including slow colonic transit [8], difficult evacuation [6], loss of sensory awareness that leads to a desire to defecate [2] and in some patients drug adverse effects, especially if opiates are consumed. Overactive bladder is a common problem in spinally injured individuals and results from a failure of the detrusor to relax during filling, and/or involuntary or reflex contractions of the bladder during filling. This 
affects the ability to defer micturition until appropriate, and the term neurogenic detrusor overactivity is sometimes used. Antimuscarinic agents are frequently used for the management of bladder symptoms in SCI and also exert a constipating effect [9]. Constipation is a doserelated adverse effect of anti-muscarinic agents [10]. It is unknown whether this constipating effect occurs through purely the physiologically predictable slowing of whole gut transit, or whether there is an additional anorectal adverse effect of these drugs.

Patients with supraconal SCI have increased rectal compliance [11]. Rectal compliance is a function of the passive properties (connective tissue) of the rectal wall and the parasympathetic input via the spinal nerves S2 and S3. A compliant rectum may predispose towards the progressive accumulation of stools and subsequent impaction.

The rectoanal inhibitory reflex (RAIR) is an enteroenteric reflex that reflects internal anal sphincter relaxation in response to rectal distension. Thiruppathy et al. [12] have shown a significant negative correlation between Wexner constipation scores and the amplitude of relaxation of the RAIR in patients with neurogenic bowel dysfunction (including SCI and multiple sclerosis). The RAIR is a quantifiable variable in the continence mechanism [12] and alteration in characteristics of the RAIR have been implicated in the aetio-pathogenesis of bowel dysfunction in SCI.

To date, there are no known studies investigating whether anti-muscarinic drugs affect anorectal physiology in spinal intact individuals or those with SCI. Our hypothesis was that anti-muscarinic agents alter rectal compliance in SCI patients and that altered rectal compliance relates to bowel symptomatology. Our primary aim was to compare rectal compliance before and after the institution of tolterodine, solifenacin or mirabegron in patients with spinal cord injuries. Tolterodine is an antagonist of the M2- and M3muscarinic receptor whilst solifenacin is a selective antagonist of the M3-muscarinic receptor. Mirabegron has an adrenoceptor mechanism of action, being a $\beta 3$-agonist and thus causes direct detrusor relaxation. As a secondary aim, we also wanted to evaluate if anorectal manometry parameters, including aspects of the RAIR, differed before and after the use of anti-muscarinic agents in this group of patients.

\section{Methods}

Thirty-five consecutive consenting patients with chronic supraconal SCI who were to be started on tolterodine or solifenacin or mirabegron for overactive bladder $(\mathrm{OAB})$ were selected. These patients attended a neurogastroenterology clinic in a tertiary referral centre and were issued either solifenacin $(n=17)$, tolterodine $(n=10)$ or mirabegron $(n=8)$. It is known that solifenacin $(5-10 \mathrm{mg})$ and tolterodine $(4 \mathrm{mg})$ are similar in anticholinergic effect on the urinary bladder and are interchangeable [13]. Since both anticholinergic drugs have an effect on M3-receptors [14] which are thought to be physiologically dominant in the gut $[13,15,16]$ it was decided to combine the data from both agents. By contrast, mirabegron $(25-50 \mathrm{mg})$ is a $\beta 3$ agonist [13]. The choice of agent was left to the prescribing clinician, these being the agents used in the Spinal Injury Unit at the Royal National Orthopaedic Hospital, Stanmore. The study was approved by the National Hospital of Neurology and Neurosurgery ethics committee and was performed in accordance with the Declaration of Helsinki.

The clinical notes of these patients were scrutinised and data collected which included demographic features, and duration since injury. Patients taking other drugs with anticholinergic action (tricyclic antidepressants, anti-histamines, anti-psychotics) were excluded. Spinally injured female patients who had previously had children were excluded to avoid the influence of obstetric-induced anorectal dysfunction. Other exclusion criteria included inflammatory bowel disease, diabetes mellitus, previous anorectal or colonic surgery and patients who refused consent for the study.

\section{Symptoms}

Symptom data were collated using the Wexner constipation [17] and Wexner incontinence [18] questionnaires, which provide validated and reproducible quantitative assessment of bowel symptoms using scores $[19,20]$. The incontinence score ranges between 0 and 20 , and the constipation score ranges between 0 and 30 , with 0 representing the absence of symptoms, and 20 or 30 the most burdensome level of symptoms. All patients completed both questionnaires.

\section{Standard anorectal physiology}

Anorectal manometry was carried out according to standardized criteria [21] with a protocol previously described [22] using a water perfused manometry system (MMS, Enschede, Netherlands) with a pump (Mui Scientific, Ontario, Canada) and controlled by the software supplied by Medical Measurement Systems (MMS, Enschede, Netherlands). No bowel preparation was given before testing. An eight channel radial water-perfused manometry system with a perfusion rate of $0.6 \mathrm{ml} / \mathrm{min}$ (MMS, Enschede, and The Netherlands) was utilized. A latex-free balloon with $300 \mathrm{ml}$ capacity was attached at the end 
of the manometry catheters (Ardmore Healthcare Limited, Amersham, UK, external diameter $3.9 \mathrm{~mm}$ ). With the subject in the left lateral position, the station pull-through technique was employed to assess anal resting pressure, maximum squeeze pressure, cough (involuntary squeeze) pressure. The Recto-Anal Inhibitory Reflex was assessed by rapidly inflating the balloon with $50 \mathrm{ml}$ air and then rapidly deflating it. Four components of the RAIR, (excitation latency, duration of excitation, percentage reduction in amplitude and total duration of recovery) were recorded [12].

\section{Measurement of rectal compliance}

Rectal compliance (normal range: $9-11 \mathrm{ml} / \mathrm{mmHg}$ ) was measured using a mechanical barostat (Distender II, G\&J Electronics, Ontario, and Canada). A special double lumen silicon catheter was used to measure compliance (Mui Scientific Inc., Ontario, Canada). A disposable polyethylene oversized non-compliant bag was attached to the distal end of this catheter (Ardmore Healthcare Limited, Amersham, UK). While one lumen was used to inflate the balloon at a fixed distending pressure, the other lumen was used to record pressure and volume measurements. With the patient in the left lateral position, the balloon was inserted in the rectum and then connected to the barostat to start a sequence of fixed distensions (at $4 \mathrm{mmHg}$ increments) each lasting one minute. Volume and pressure readings were fed into a statistical programme (Protocol Plus Scanner, G\&J Electronics, Ontario, and Canada) to calculate rectal compliance.

\section{Study design}

Anorectal manometry, rectal compliance recordings and bowel symptoms questionnaires were performed prior to the commencement of muscarinic antagonists or mirabegron and then 12 weeks (range 12-14) after initiation of therapy.

\section{Statistical analysis}

Since not all data were normally distributed, based on the Kolmogorov-Smirnov test, the Wilcoxon Signed Ranks Test was used to analyse pre- and post- treatment data. A $p$-value of $<0.05$ was considered significant. Data are presented as mean (SD) for normal data and median (inter-quartile-range) for non-parametric data. Non parametric measure of rank correlation was performed by Spearman's rank correlation ( $\rho$ - coefficient). Statistical analysis was performed by the use of the statistical software package SPSS statistics version 17 for Windows (IBM, New York, USA).

\section{Results}

\section{Patient data}

In total 35 patients with supraconal SCI [22 male, mean age 47 years (24-76)] were recruited, and were prescribed an antimuscarinic agent to treat $\mathrm{OAB}$ [solifenacin (17) or tolterodine (10) or mirabegron (8)]. The median duration since sustaining injury was 16 months (5-23). The median followup period was 16 months (10-22). All patients had complete spinal injury (American Spinal Injury Association Scale A) AIS-A).

\section{Anal manometry and rectal compliance}

Anal sphincter function parameters of resting, squeeze and cough pressure were unchanged after anti-muscarinic treatment (Table 1). Rectal compliance was significantly raised after anti-muscarinic treatment $(19.0(8.9-29.7) \mathrm{ml} / \mathrm{mmHg}$ vs 23.6 (15.9-31) $\mathrm{ml} / \mathrm{mmHg} p=0.001$ ) (Fig. 1).

There were no statistically significant changes in resting squeeze and cough pressures after mirabegron (Table 2). There was no change in rectal compliance after mirabegron treatment (17.8 (7.4-28.4) $\mathrm{ml} / \mathrm{mmHg}$ vs 16.9 (9.3-28.2) $\mathrm{ml} /$ $\operatorname{mmHg} p=0.562$ ) (Fig. 1).

\section{Rectoanal inhibitory reflex parameters}

When analyzing the components of the RAIR before and after anti-muscarinic treatment, the percent amplitude of maximal sphincter relaxation was decreased and excitation latency was increased [Table 1]. There was no significant change in the duration of recovery of the RAIR.

Mirabegron was not associated with change in any of the RAIR parameters comparing before and after treatment [Table 2].

\section{Questionnaire}

There was a significant increase of the Wexner Constipation Score after anti-muscarinic treatment (Fig. 2), but not after mirabegron [Tables 1,2]. There was no significant change in the Wexner Incontinence Score for either antimuscarinics or mirabegron [Tables 1, 2].

\section{Relationship between rectal compliance and symptom change}

There was a significant correlation between change in rectal compliance and change in Wexner Constipation Score [compliance $5.6(-0.8-10.5) \mathrm{ml} / \mathrm{mmHg}$ vs Wexner score 7 $(0-14), \rho=0.597, p=0.011]$. Thus, increasing compliance of the rectum is associated with worsening of constipation 
Table 1 Anorectal physiology data (anti-muscarinic)

\begin{tabular}{lccccc}
\hline & Normal range & Pre-treatment & Post-treatment & Change & $p$-value \\
\hline Wexner incontinence score $(0-20)$ & & $12(8-15.5)$ & $11(7-14)$ & $-1.1(-1.5-1)$ & 0.323 \\
Wexner constipation score $(0-30)$ & & $11(8-16.5)$ & $19(13.5-25)$ & $8.4(4.5-10)$ & 0.001 \\
Resting anal pressure $\left(\mathrm{cmH}_{2} \mathrm{O}\right)$ & $60-160$ & $84(71-108)$ & $82(72-111)$ & $-3(-10-7)$ & 0.072 \\
Squeeze pressure $\left(\mathrm{cmH}_{2} \mathrm{O}\right)$ & $50-180$ (female) $60-220$ (male) & $111(84-156)$ & $114(83-149)$ & $3(-1-7)$ & 0.817 \\
Cough pressure $\left(\mathrm{cmH}_{2} \mathrm{O}\right)$ & $50-180$ (female) 60-220 (male) & $81(64-131)$ & $83(68-133)$ & $3(-3-9)$ & 0.686 \\
RAIR amplitude reduction $(\%)$ & & $47(42-62)$ & $36(31-47)$ & $-11(-16--4)$ & $<0.001$ \\
RAIR excitation latency $(\mathrm{s})$ & & $1.3(0.7-2.3)$ & $2.1(1.0-3.1)$ & $0.9(0.3-1.2)$ & 0.006 \\
RAIR recovery $(\mathrm{s})$ & & $6.2(4.6-10.1)$ & $6.4(4.8-9.4)$ & $0.1(-0.2-0.6)$ & 0.624 \\
\hline
\end{tabular}

The median values (inter-quartile range) in patients with supraconal SCI pre- and post-treatment with a muscarinic antagonist (tolterodine or solifenacin) for bladder overactivity are shown. The ranges are in parentheses. The data were analysed using the Wilcoxon Signed Ranks test. A $p$-value $<0.05$ was considered to be significant

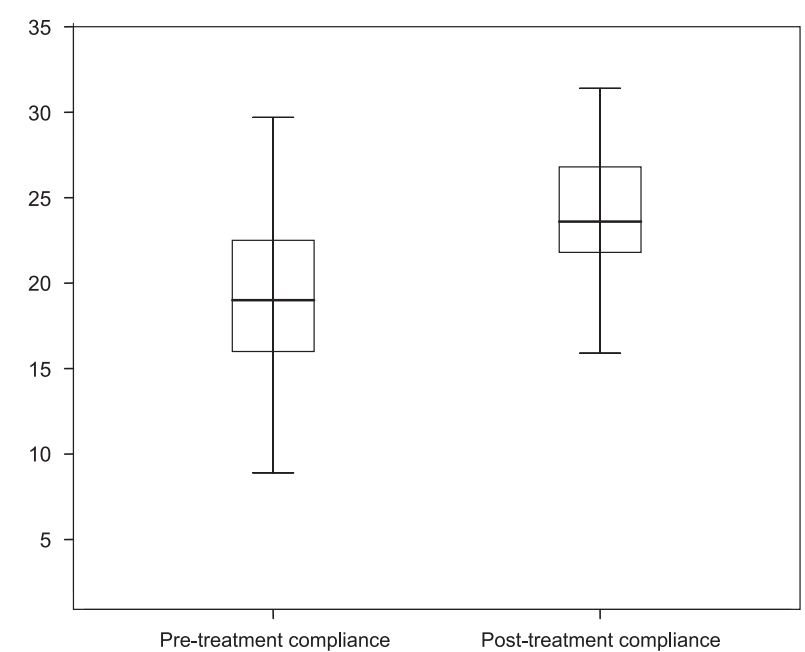

Fig. 1 Box plots showing a significant increase in rectal compliance $(\mathrm{ml} / \mathrm{mmHg})$ before and after antimuscarinic therapy showing median and inter-quartile range. $Y$-axis-rectal compliance $(\mathrm{ml} / \mathrm{mmHg})$

after anti-muscarinic therapy. No such relationship was seen with mirabegron

\section{Discussion}

The key original finding of this study is that anti-muscarinic drugs alter the compliance of the rectum in supraconal spinal cord injury. Baseline rectal compliance is higher in supraconal injured patients than in spinally intact patients and, antimuscarinic agents increased further the rectal compliance. Additionally, the data show that resting anal pressure, anal squeeze pressure and cough pressure were not affected by the introduction of an anti-muscarinic drug (solifenacin or tolterodine).

The Neurogenic Bowel Dysfunction (NBD) scale was not used as it is a cumulative score which reflects both constipation as well as faecal incontinence. As such it would not be sensitive to the hypothesised antimuscarinicinduced change in constipation. Secondly, looking at individual questions of the Wexner and NBD scores has not been validated. Therefore, breakdown of each question within the Wexner constipation was not undertaken.

Muscarinic receptors are located throughout the body, and their stimulation produces characteristic physiological functions depending on location and subtype of receptor. Five receptor subtypes are recognized (M1-M5) (20), but the function of M4 and M5 subtypes is not yet clear [23] The detrusor muscle contains all these receptors but predominantly M2 and M3 (in the ratio 3:1) [15, 24]. Stimulation of the minority M3 receptor produces detrusor contractions $[16,25]$. The same proportion of muscarinic receptors (M2: M3-3:1) is seen in ileal, gastric and colonic mucosa $[16,26]$. Activation of M3 receptors stimulates contractility of the bowel. It will follow that muscarinic antagonists may produce complementary actions, namely, attenuation of bladder contraction and bowel motility, resulting in retention of urine and constipation, respectively. A double-blinded study in healthy volunteers compared gastrointestinal transit times and bowel habits between individuals taking Tolterodine or placebo for 6 days. It showed that the anti-muscarinic tolterodine did not significantly affect ease of defecation, stool consistency, gastrointestinal or colonic transit [10]. The main excitatory neurotransmitter in the gut and urinary bladder is acetylcholine, which acts on muscarinic receptors to facilitate its action. There are many similarities in muscarinic regulation of smooth muscle contractility in both the urinary bladder and gut [10]. Activation of the minority M3 subtype is responsible for stimulating contractions in the bowel [27]. M1 antagonists seem to accelerate transit and reduce rectal pressure (ie increase compliance).

The mechanism by which muscarinic antagonists produce constipation is by inhibiting the contractility of smooth 
Table 2 Anorectal physiology data (mirabegron)

\begin{tabular}{llcccc}
\hline & Normal range & Pre-treatment & Post-treatment & Change & $p$-value \\
\hline Wexner incontinence score $(0-20)$ & & $12(6.5-15.5)$ & $13(7-15.5)$ & $1.2(-1-2)$ & 0.423 \\
Wexner constipation score $(0-30)$ & & $12(7.5-16)$ & $12(8.5-21)$ & $0.6(-1.5-2)$ & 0.268 \\
Resting anal pressure $\left(\mathrm{cmH}_{2} \mathrm{O}\right)$ & $60-160$ & $80(65-106)$ & $83(75-110)$ & $4(-4-9)$ & 0.068 \\
Squeeze pressure $\left(\mathrm{cmH}_{2} \mathrm{O}\right)$ & $50-180$ (female) $60-220$ (male) & $113(87-189)$ & $115(86-155)$ & $2(-4-12)$ & 0.879 \\
Cough pressure $\left(\mathrm{cmH}_{2} \mathrm{O}\right)$ & $50-180$ (female) 60-220 (male) & $79(70-122)$ & $82(63-129)$ & $4(-4-14)$ & 0.563 \\
\hline
\end{tabular}

The median values (inter-quartile range) in patients with supraconal SCI pre- and post-treatment with a mirabegron for bladder overactivity are shown. The ranges are in parentheses. The data were analysed using the Wilcoxon Signed Ranks test. A $p$-value $<0.05$ was considered to be significant

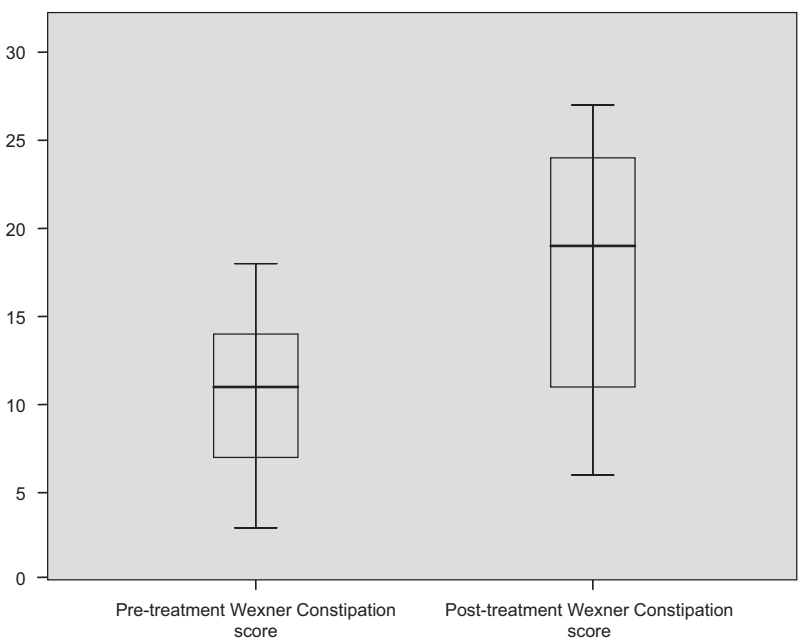

Fig. 2 Box plots showing an increase in Wexner Constipation score before and after antimuscarinic therapy showing median and interquartile range

muscle in the bowel as a result of antagonising the effect of acetylcholine. Bharucha et al. showed that although tolterodine did significantly reduce the number of bowel movements it did not significantly affect gastrointestinal transit when compared with placebo therapy [10]. In contrast, atropine (another non-specific muscarinic antagonist) markedly prolonged oro-ileal transit in humans and delayed colonic transit in a dog having rapid gastrointestinal transit [28]. This could be due to the stronger affinity of atropine for M3 than for M2 receptors, as M3 is primarily responsible for bowel smooth muscle contractility [29].

Mirabegron is an alternative new drug used in OAB. It is a $\beta 3$ agonist and stimulates these receptors found in the detrusor muscle and urothelium. It causes direct detrusor relaxation. The actual cellular pathophysiology of this drug is not fully clear. The starting dose is $25 \mathrm{mg}$ and it can be increased to $50 \mathrm{mg}$ for effect. A number of trials have been done to investigate the potential of the drug alone or in combination with anti-muscarinic agents. In our study, there was no significant difference in Wexner scores and anorectal physiological parameter before and after introducing it.

Rectal compliance is influenced by the parasympathetic system (S2, S3, S4) arising from the spinal cord and the intrinsic nervous system within the bowel wall. The intrinsic nervous system and extrinsic autonomic nervous systems are modulated by the signals from the cortex. It is evident that the pelvic and rectal nerves convey excitatory cholinergic input to the gut as well as inhibitory nonadrenergic non-cholinergic (NANC) input (via nitric oxide and/or purines) [30]. When a complete supraconal injury (spinal cord injury above L1) occurs, this modulation may be attenuated, and the resulting increased rectal compliance is a result of the unmodulated activity of the parasympathetic sacral outflow. By blocking muscarinic receptors using peripherally acting anti-muscarinic agents and the absence of cortical modulation, increase in rectal compliance in supraconal spinal injuries may be causally related to an increase in parasympathetic tone. These effects may be moderated by the loss of inhibitory NANC tone.

A limitation of this non-randomised study with relatively small patient numbers is that the data are subject to Type II error as this was a non-powered study. We were careful not to assess multiple anorectal physiology parameters, and focussed on those for which there was a biologically plausible anticholinergic mechanism. An additional limitation of the study design is that this was an uncontrolled study, and as such prone to bias as well as the potential for observed post-treatment data to reflect a reversion to the mean. We attempted to limit this by only using selected, reproducible anorectal physiology parameters.

In conclusion, this study has demonstrated a significant rise in rectal compliance and a significant amplitude reduction in the RAIR following the use of muscarinic antagonists in those with supraconal SCI. These changes may predispose towards constipation. In the absence of cortical modulation, in patients with a SCI level above T5, sympathetic activity is effectively dissociated, since whilst tonic sympathetic activity is reduced there is reflex hyperactivity. The effects of these drugs underline the importance 
of tonic parasympathetic input to rectal compliance and anorectal reflex functioning. Future studies should include using the 5HT4 receptor agonist prucalopride and mucosal local anaesthetic agents to investigate whether they improve NBD symptoms and cause an alteration in rectal compliance and reflex physiology. Also, the constipating effects of antimuscarinic agent might be exploited to treat faecal incontinence in patients with associated bladder dysfunction.

\section{Data archiving}

The datasets generated and/or analysed during the current study are available from the corresponding author on reasonable request

Author contributions AP was majorly responsible for the conduct of the study in terms of data collection, statistical analysis and major write up of the manuscript. AE was the initiator of the project, reviewer of manuscript and involved in writing up of part of the manuscript. PT was involved in data analysis and contributing additional material to the discussion. GP was involved in data collection and contributing additional material towards the Methods section.

Funding No funding was used from any sources in the conduct and write up of this study.

\section{Compliance with ethical standards}

Statement of ethics We certify that all applicable institutional and governmental regulations concerning the ethical use of patients were followed during the course of this research.

Conflict of interest The authors declare that they have no conflict of interest.

Publisher's note: Springer Nature remains neutral with regard to jurisdictional claims in published maps and institutional affiliations.

\section{References}

1. Krogh K, Nielsen J, Djurhuus JC, Mosdal C, Sabroe S, Laurberg S. Colorectal function in patients with spinal cord lesions. Dis Colon Rectum. 1997;40:1233-9.

2. Glickman S, Kamm MA. Bowel dysfunction in spinal-cord-injury patients. Lancet. 1996;347:1651.

3. Lynch AC. Bowel dysfunction following spinal cord injury: a description of bowel function in a spinal cord-injured population and comparison with age and gender matched controls. Spinal Cord. 2000;38:717.

4. Gore RM, Mintzer RA, Calenoff L. Gastrointestinal complications of spinal cord injury. Spine (Phila, Pa 1976). 1981;6:538.

5. De Looze D. Constipation and other chronic gastrointestinal problems in spinal cord injury patients. Spinal Cord. 1998; 36:63-6.

6. Han TR, Kim JH, Kwon BS. Chronic gastrointestinal problems and bowel dysfunction in patients with spinal cord injury. Spinal Cord. 1998;36:485-90.
7. Ng C, Prott G, Rutkowski S, Li Y, Hansen R, Kellow J, et al. Gastrointestinal symptoms in spinal cord injury: relationships with level of injury and psychologic factors. Dis Colon Rectum. 2005;48:1562-8.

8. Krogh K, Mosdal C, Laurberg S. Gastrointestinal and segmental colonic transit times in patients with acute and chronic spinal cord lesions. Spinal Cord. 2000;38:615-21.

9. Andersson KE, Yoshida M. Antimuscarinics and the overactive detrusor--which is the main mechanism of action? Eur Urol. 2003;43:1-5.

10. Bharucha AE, Seide B, Guan Z, Andrews CN, Zinsmeister AR. Effect of tolterodine on gastrointestinal transit and bowel habits in healthy subjects. Neurogastroenterol Motil. 2008;20:643-8.

11. Trivedi PM, Kumar L, Emmanuel A. Altered colorectal compliance and anorectal physiology in upper and lower motor neurone spinal injury may explain bowel symptom pattern. Am J Gastroenterol. 2016;111:552-60.

12. Thiruppathy K, Roy A, Preziosi G, Pannicker J, Emmanuel A. Morphological abnormalities of the recto-anal inhibitory reflex reflects symptom pattern in neurogenic bowel. Dig Dis Sci. 2012;57:1908-14.

13. Chapple C, Steers W, Norton P, Millard R, Kralidis G, Glavind K, et al. A pooled analysis of three phase III studies to investigate the efficacy, tolerability and safety of darifenacin, a muscarinic M3 selective receptor antagonist, in the treatment of overactive bladder. BJU Int. 2005;95:993-1001.

14. Chapple C, Cardozo L, Nitti V, Siddiqui E, Michel M. Mirabegron in overactive bladder: A Review of efficacy, safety, and tolerability. Neurourol Urodyn. 2014;33:17-30.

15. Hegde SS, Choppin A, Bonhaus D, Briaud S, Loeb M, Moy TM, et al. Functional role of M2 and M3 muscarinic receptors in the urinary bladder of rats in vitro and in vivo. $\mathrm{Br} \mathrm{J}$ Pharmacol. 1997;120:1409-18.

16. Chess-Williams R, Chapple CR, Yamanishi T, Yasuda K, Sellers DJ. The minor population of M3-receptors mediate contraction of human detrusor muscle in vitro. J Auton Pharmacol. 2001;21:243-8.

17. Agachan F, Chen T, Pfeifer J, Reissman P, Wexner SD. A constipation scoring system to simplify evaluation and management of constipated patients. Dis Colon Rectum. 1996;39:681-5.

18. Jorge JMN, Wexner SD. Etiology and management of fecal incontinence. Dis Colon Rectum. 1993;36:77-97.

19. Vaizey CJ, Carapeti E, Cahill JA, Kamm MA. Prospective comparison of faecal incontinence grading systems. Gut. 1999; 44:77-80.

20. Holzer B, Rosen HR, Novi G, Ausch C, Hölbling N, Hofmann M. et al. Sacral nerve stimulation in patients with severe constipation. Dis Colon Rectum. 2008;51:524-9.

21. Diamant NE, Kamm MA, Wald A, Whitehead WE. AGA technical review on anorectal testing techniques. Gastroenterology. 1999;116:735-60.

22. Preziosi G, Raptis DA, Storrie J, Raeburn A, Fowler CJ, Emmanuel A. Bowel biofeedback9treatment in patients with multiple sclerosis and bowel symptoms. Dis Colon Rectum. 2011;54:1114-21.

23. Caulfield MP, Birdsall NJ. International Union of Pharmacology. XVII. Classification of muscarinic acetylcholine receptors. Pharmacol Rev. 1998;50:279-90.

24. Wang P, Luthin GR, Ruggieri MR. Muscarinic acetylcholine receptor subtypes mediating urinary bladder contractility and coupling to GTP binding proteins. J Pharmacol Exp Ther. 1995;273:959-66.

25. Fetscher C, Fleichman M, Schmidt M, Krege S, Michel MC. M3 muscarinic receptors mediate contraction of human urinary bladder. Br J Pharmacol. 2002;136:641-4. 
26. Uchiyama T, Chess-Williams R. Muscarinic receptor subtypes of the bladder and gastrointestinal tract. J Smooth Muscle Res. 2004;40:237-47.

27. Abrams P. Muscarinic receptors: their distribution and function in body systems, and the implications for treating overactive bladder. Br J Pharmacol. 2006;148:565.

28. Chiba T, Bharucha AE, Thomforde GM, Kost LJ, Phillips SF. Model of rapid gastrointestinal transit in dogs: effects of muscarinic antagonists and a nitric oxide synthase inhibitor. Neurogastroenterol Motil. 2002;14:535-41.

29. Eglen RM, Choppin A, Watson N. Therapeutic opportunities from muscarinic receptor research. Trends Pharmacol Sci. 2001; 22:409-14

30. Browning KN, Travagli RA. Central nervous system control of gastrointestinal motility and secretion and modulation of gastrointestinal functions. Compr Physiol. 2014;4:1339-68. 